\title{
Nondestructive Detection of Valves Using Acoustic Emission Technique
}

\author{
Jin Yan, ${ }^{1}$ Yang Heng-hu, ${ }^{2}$ Yang Hong, ${ }^{2}$ Zhang Feng, ${ }^{2}$ Liu Zhen, \\ Wang Ping, ${ }^{2}$ and Yang Yan ${ }^{2}$ \\ ${ }^{1}$ Zhoushan Library, Chongqing University of Technology, Chongqing 400054, China \\ ${ }^{2}$ College of Mechanical Engineering, Chongqing University of Technology, Chongqing 400054, China \\ Correspondence should be addressed to Yang Yan; yangyan@cqut.edu.cn
}

Received 18 September 2014; Revised 25 January 2015; Accepted 24 February 2015

Academic Editor: Anna Richelli

Copyright (C) 2015 Jin Yan et al. This is an open access article distributed under the Creative Commons Attribution License, which permits unrestricted use, distribution, and reproduction in any medium, provided the original work is properly cited.

The applications of acoustic emission (AE) technique in detection of valves are presented in this review, and the theoretical models and experimental results of nondestructive detection of valves using $\mathrm{AE}$ are provided. The generation of $\mathrm{AE}$ signals and the basic composition of AE detection system are briefly explained. The applications of AE technique in valves are focused on condition monitoring, failure, cavitation detection, and the development of portable measuring devices. All results prove that the AE technique works well in the detection of valves.

\section{Introduction}

The valve plays a key role in some fields such as the nuclear power plant, transport of corrosive fluid, controlling of water, and oil and gas pipelines. The serious problems will occur when the valves are failure, such as waste of resources, serious environmental pollution, huge repair costs, and threat to lives [1-3]. Some researchers have found that one main failure type of valves is the fluid leakage induced by sealing surface failure [4]. In addition, cavitations of valves are also interesting. With the application of valves becoming more and more wide, many methods for detection of valves are developed.

Some techniques have been used to diagnose leakage of a valve. Tandon and Choudhury briefly introduced some methods for detection of leakage in valves [5]. These methods could be narrated as follows: the shock pulse method, acoustic emission (AE), ultrasonic leak detection, vibration analysis below $20 \mathrm{kHz}$, and other methods including the thermography, specific gas detection, and pneumatic and pressure change. However, some of them are not popular in valves because of some inherent characteristics of themselves such as the temperature influences of environment on thermography and the constant pressure changes of valves. It is well known that acoustic emission sensing is a reliable intelligent technique for monitoring status of materials under stress. In the last decades, the applications of $\mathrm{AE}$ technique in nondestructive detection of valves were developed greatly. The AE signals introduced by leakage of valves belong to high frequency waves, and it cannot be easily interfered by the ambient noise [6]. The AE technique also can detect the leakage without disassembling valves [7].

\section{The Acoustic Emission (AE) Technique}

2.1. The Principles of Acoustic Emission (AE). The acoustic emission (AE) technique, which is a nondestructive testing method, is a technology that can diagnose the working state of mechanical parts through detecting and analyzing the transient elastic wave generated by a rapid release of local energy sources within a material such as cracking, rubbing, polishing, impacting, cavitations, and leakage [8]. The AE technique with high sensitivity [9] was widely used in various fields such as the process monitoring of mechanical manufacturing $[10,11]$, construction industry [12], material researches $[13,14]$, and leakage detection of pipelines $[15,16]$. Jomdecha et al. used the AE parameters including amplitude, counts, click rate, and time to assess different types of corrosion. The corrosion position achieved by this method had a good 
agreement with that obtained by experiment [17]. Lura et al. had a study on the self-drying phenomenon of cement slurry with the AE technique and obtained the conversion time of the liquid phase and solid phase [18]. Ukpai et al. detected the erosive wear of X65 carbon steel using AE technology and found that no obvious damage existed if the AE energy was below the threshold value. This research provided a new method for studies of materials, design, and manufacture of machine [14].

2.2. The Acoustic Emission (AE) in Valves. Researchers have found that the AE signals also exist in the process of fluid leakage such as the valve leakage [19]. It belongs to high frequency stress wave induced by the turbulence, which is due to the random flow when the fluid goes through the leak hole of valve [20]. The frequency varies from $100 \mathrm{kHz}$ to $1 \mathrm{MHz}$ [4], and it can be easily identified by environmental noise from the factory [21]. El-Shorbagy found the measurement of flow rate and the automatic online control could be achieved through monitoring the sound level of valve noise [22]. Sharif and Grosvenor presented an experiment on the leakage of compressed air through an industrial control valve and analyzed the frequency spectrum of the AE signal. The results demonstrated that the frequency components related with leakage could be clearly picked up from $\mathrm{AE}$ signal with background noise [23]. Lee et al. studied the AE characteristics of leakage in two valves (the steam ball valve and water ball valve) under a situation of different leakage modes, and it can be concluded that the leakage rate of valves is directly proportional to the sound amplitude [24]. Recently, the rate of gas leakage of a valve was estimated by the theoretical relationship between the features of AE signals and internal leakage rate of valves [25]. Thus, it is feasible that AE technique can be applied in the inner leakage detection of valves. The process of estimating the leakage rate is shown in Figure 1.

\section{Experimental Setup}

To estimate the leakage rate of a valve, many researchers conducted the experiments and the theoretical investigations on the relationship between the $\mathrm{AE}$ signal and the valve leakage. The experiment system which consists of the leakage system and the $\mathrm{AE}$ measurement system is shown in Figure 2.

For leakage system, valves are chosen to be the test subjects, which mainly are ball and globe balls because of their wide applications. In these experiments, different sizes of valves were tested in order to achieve the relationship between the leakage rate and the valve size. The leakage was generated by three ways: the artificial destruction of the valves [26], incomplete closure [27], or simulated leakage source [28].

$\mathrm{AE}$ measurement system consists of the AE sensor, the preamplifier, the band pass filter, amplifier, and the real-time signal analyzer. The AE sensor with a natural frequency of $150 \mathrm{kHz}$ [29] is used to obtain the AE signal. The preamplifier with $60 \mathrm{~dB}$ gain can amplify the $\mathrm{AE}$ signals in order to be suitable for subsequent processing. The band pass filter of

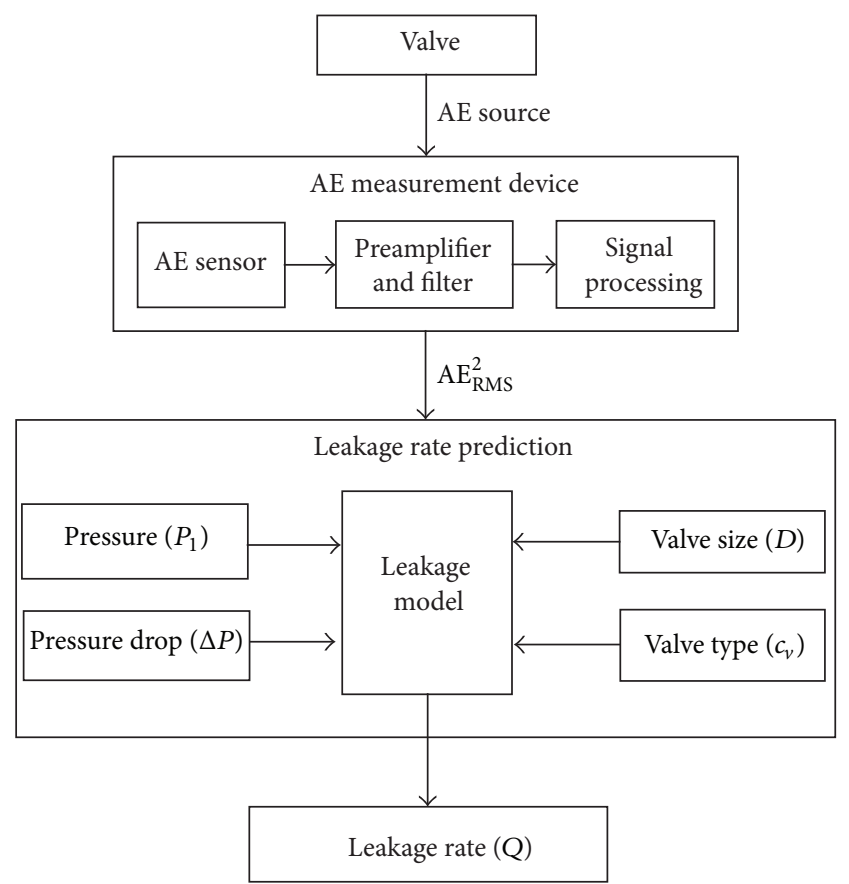

FIgURE 1: Processes to predict valve leakage rate by acoustic emission [27].

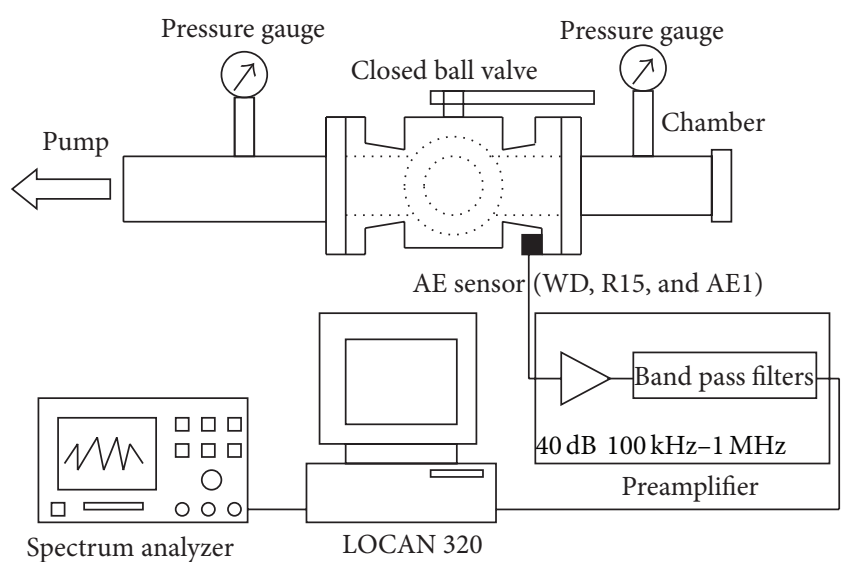

FIgURE 2: Diagram of experimental setup [28].

$100 \mathrm{kHz}-300 \mathrm{kHz}$ is in the experiment to obtain the ideal range of frequency. The output $\mathrm{AE}$ signal is sent to the amplifier which is set at $20 \mathrm{~dB}$. Then its waveform is recorded by a real-time signal analyzer with a maximum sampling rate of $10 \mathrm{MHz}$.

\section{The Processing Methods of AE Signal}

4.1. The Parameters Analysis of AE Signals in Valves. Parameter analysis (i.e., simplified waveform parameters) is a dominant method in the signal processing field. Compared with the full waveform analysis method, the parameters analysis has many advances, for example, fast recording and rapid 


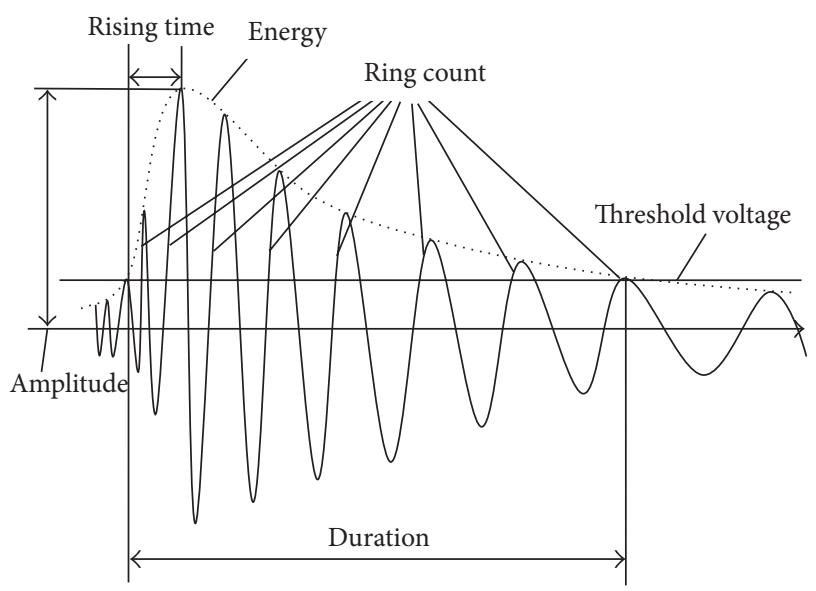

FIGURE 3: Definition of simplified waveform parameters of AE signal [31].

processing. Many parameters, such as the rise time, ringdown counts, amplitude, peak, duration and root mean square (RMS) value, and kurtosis, were analyzed using this method [30, 31]. The parameters are shown in Figure 3.

Dickey et al. [32] found that the peak amplitude of $\mathrm{AE}$ signal in frequency domain was tightly related to transducer response or valve geometry. Gao et al. presented the relationship between the AE parameters and the parameters of fluid filed and valves. It was found that the ring-down counts, energy, amplitude, or RMS value of AE signals induced by leakage was directly proportional to the inlet pressure [33]. However, the AE signal induced by the valve leakage is continuous. Two parameters, the effective voltage (RMS) and average signal level (ASL), are used to describe the AE signal. RMS and ASL are the root-mean-square value and average of signal level within sample time, respectively [34]. Kaewwaewnoi et al. found that a good correlation existed between the leakage rate and the ASL. An equation related to the valve leakage rate was achieved [35]. Many literatures presented the average energy of AE signal (AErms) as a more sensitive parameter of valve. Chen et al. evaluated the various parameters of AE signals in terms of their capability of estimating the internal leakage rate of a water hydraulic cylinder. They have shown the RMS value was more suitable to interpret AE signals generated by internal leakage [36]. Kaewwaewnoi et al. also found the relationship between the AErms and the parameters such as inlet pressure levels, valve sizes, and valve types. The AErms could be used to predict the actual leakage rate qualitatively [27, 37]. In [38], the characteristic of AE signal in frequency domain and a relationship between the AE signal and the leakage rate were studied in a ball valve. Jiang et al. explored the function between the Reynolds number $(\mathrm{Re})$ and the sound pressure level of gas leakage with $\mathrm{AE}$ technique. The mass of gas leakage in the flow field was calculated, which is the foundation for the detection of the valve leak [39]. Gao et al. presented the quantitative relationship between the valve leakage rate of coal-fired power plants and the AErms. Its precision was verified by the practice results [40].
Based on the above, the following results could be summarized.

(1) The power spectrum density (PSD) of fresh water was greater than the compressed air because the acoustic impedance of water was closer to that of the valve material.

(2) The AErms increased with inlet pressure, which was similar to the relationship between the AErms and the leakage rate.

(3) The AErms was inversely proportional to the size of valve.

(4) The AErms was inversely proportional to the flow coefficient.

4.2. The New Analysis Methods of AE Signals. With the development of technology, many new signal processing methods are proposed and applied to practice fields. To extract the useful information from the AE signals, some methods are used, such as fast Fourier transform (FFT), wavelet transform (WT), and Hilbert-Huang transform (HHT) [41].

In [42], the adaptive filtering technique, which enhances the AE signals generated by diesel fuel injection, was proved to work well in detecting small changes. A statistical noise removal technique called Rao-Blackwellised particle filter (RBPF) was proposed to improve the signal noise ratio (SNR) of $\mathrm{AE}$ signals. Based on the analysis of the AE data, it was demonstrated that the RBPF was feasible in enhancing the SNR of AE signals [43]. An improved wavelet double-threshold denoising optimization, which could largely increase the SNR value of AE signal, was presented and the least squares support vector machine (LSSVM) method was used to recognize working conditions of pipelines [44].

Ahadi and Bakhtiar proposed the tuned wavelet which is a guiding method of selecting mother wavelet applied in wavelet transform (WT). It became the standard of selecting mother wavelet [45]. Lu et al. investigated the effectiveness of time-frequency analysis of the AE signals by the tension tests of carbon fiber reinforced plastic (CFRP) composites, where short-time Fourier transform (SFT), wavelet transform, and Hilbert-Huang transform were used. It was found that the Hilbert-Huang transform (HHT) had the advantage in dealing with nonstationary signals [46]. Yang et al. also used HHT to study the AE signal induced by grinding burn, and good results were achieved [47]. Liang and Zhang presented a new leakage detection program for pipeline, which includes the wavelet packet analysis (WPA), principal component analysis (PCA), Gaussian mixture model (GMM), and the Bayesian information criterion (BIC). It was effective in experiments [48]. Le et al. presented a method to detect leakage of an electrohydraulic cylinder based on multilayer perceptron (MLP) type neural networks, which could successfully detect leakage in the single or multiple fluid power systems [49]. Sun et al. proposed a small leak feature extraction and a recognition method based on local mean decomposition (LMD) envelope spectrum entropy and support vector machine (SVM) [50]. Park developed a method to diagnose the different failure 
modes of the valve with the AE sensors and a neural network model [51]. In [52], an improved wavelet neural network (WNN) algorithm which combines with modified particle swarm optimization (MPSO) was presented to overcome the problems such as shortage in responding speed and learning ability. The energy and square error of the signals in the detail levels are input to the trained WNN to estimate the tool wear. Comparing with conventional BP neutral network, the advantage of the improved WNN algorithm involved a simple structure and faster converge conventional WNN and genetic algorithm-based WNN. Jafari et al. used an artificial neural network (ANN) to distinguish the fault types in valves by the $\mathrm{AE}$ features. The results were well satisfied with experimental results [53]. Mao et al. had a real-time fast Fourier transform (FFT) analysis of AE signals, which was developed for monitoring laser welding processes. The results were in good agreement with experimental data [54]. Antonaci et al. analyzed the AE signals using FFT to examine the frequency distribution during the microcracking process. The method for fatigue damage evolution with AE signal was proved to be effective [55].

\section{The Applications of AE Technique in Valves Detection}

5.1. The Condition Monitoring of Valves. With the development of the technique, it is possible to monitor the operating condition of critical valves through the correlation between the AE parameters and leakage rate. The purpose is that the maintenance or replacement can be performed prior to the loss of safety function of the critical valves. The condition monitoring is mainly used for the valves in nuclear plants.

Allen et al. used the advanced monitoring diagnostics to detect two fundamental types of failure in the valve used in nuclear power plant. They realized the online judgment of the valve failure modes through the comparative analysis between the data measured and the earlier model analysis [56]. Haynes evaluated three diagnostic monitoring methods in the check valve, which contained the acoustic emission and ultrasonic and magnetic flux. They found that the combination of acoustic emission with either ultrasonic flux or magnetic flux was significant in detecting operating conditions of the check valve [57]. Lee Y et al. developed a condition monitoring system of check valves using the AE technique and neural network. In this system, the AE signal acquired by sensor passed through a signal condition. The process includes rejection of background noise, amplification, analogue to digital conversion, and extract of feature points. The developed system finished timely detection of failure of valves, successfully [58]. Lee and Kim et al. systematically studied the relations between AErms and failure modes such as disk wear and foreign object of check valves. In their study, an advanced condition monitoring technique based on AE detection and artificial neural networks was applied to the valve, which could successfully finish the evaluation of different types of failure modes [26, 59, 60]. The schematic diagram for condition monitoring test of the valve is shown in Figure 4. Boken developed a monitoring

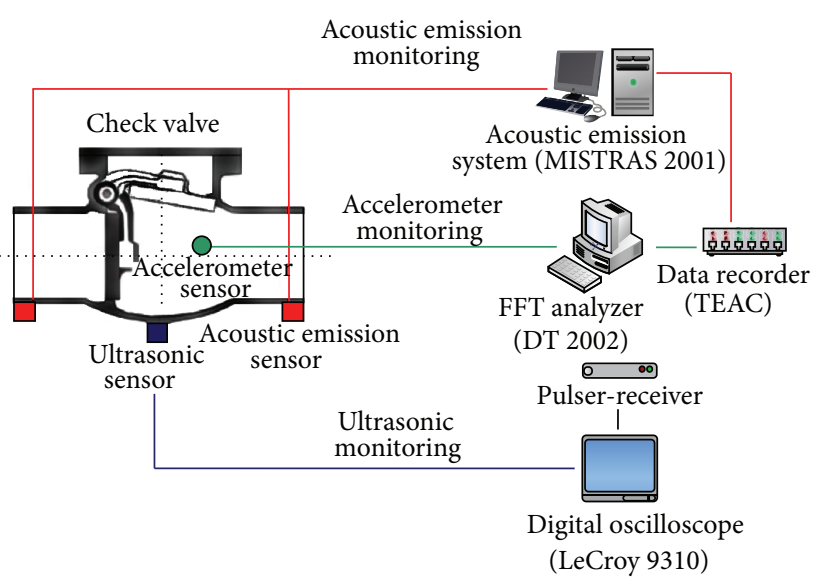

FIGURE 4: The schematic diagram for condition monitoring test of the check valve [60].

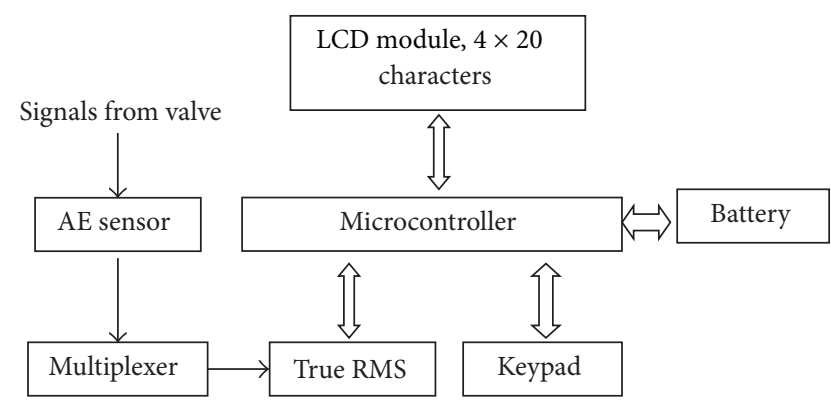

Figure 5: Block diagram of the system [37].

system of valves through the comparison of the AE signals measured practically and a memory stored in before [61]. Shukri et al. discussed the effectiveness of AE technique as a fault detection monitoring system on control valves based on statistical analysis parameters. And a real-time AE measurement system was established and tested, which could be applied to distinguish the operating states of control valves [62].

5.2. The Developments of Smart Portable Devices. The devices employed to detect the leakage of valves with the $\mathrm{AE}$ technology are usually huge and inconvenient to move. It is particularly inadequate for detecting the leakage of valves applied in engineering fields. To solve the problems and reduce the cost [63], some researchers devote themselves to the inventions and improvements of portable devices for leakage detection of valves based on the previous studies. The main idea is that those devices use a sensor to detect the sensitive parameter of the AE signal generated by leakage of valves and then have recognition or diagnosis on the leakage based on the microprocessor. Accuracy is sacrificed a little with this method in order to get the great system simplified and cost reduction. The diagram of system is shown in Figure 5. 


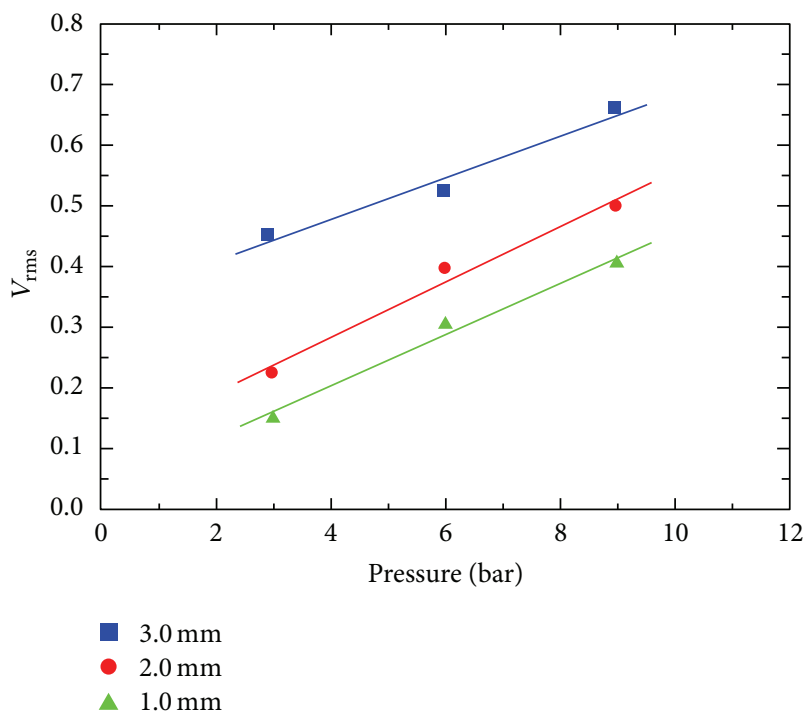

(a)

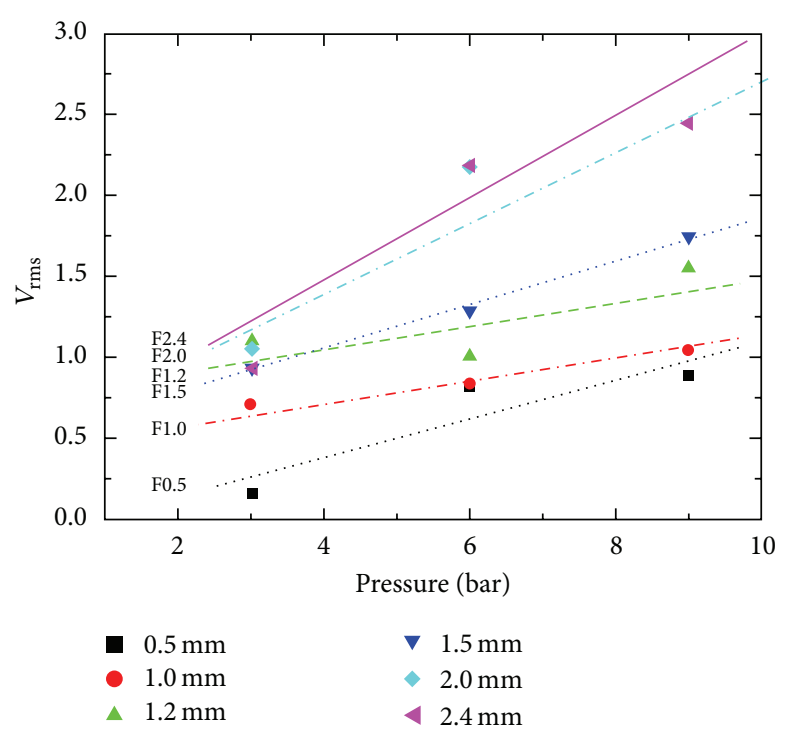

(b)

FIGURE 6: RMS values of the acoustic signals: (a) disk wear and (b) foreign objects [70].

Jomdecha et al. developed a system that consists of a field programmable gate array-PC (FPGA-PC) and three $\mathrm{AE}$ sensors with $150 \mathrm{kHz}$ resonant frequency, which was very good at locating the $\mathrm{AE}$ source from the corrosion in austenitic stainless steel [64]. Furthermore, a system based on FPGA-PC and LOCAN 320 AE analyzer was developed. Through the analysis of amplitude, counts, hits, and time of AE signals from corrosion, different types of corrosion could be identified [17]. The acoustic valve leak detector (AVLD), developed by the David Taylor Naval Ship RID Center (DTNSRDC), was currently being used for troubleshooting, overhaul planning, and a systematic preventive maintenance program for seawater valves [65]. Noipitak et al. presented a relative calibration method for an internal valve leakage rate measurement system based on the microcontroller and $\mathrm{AE}$ methods. It reduced the recalibration time and the cost, which laid a foundation for the application of $\mathrm{AE}$ technique in valves [28]. Prateepasen et al. developed a smart portable noninvasive instrument for detection of internal air leakage of a valve using $\mathrm{AE}$ signals. The measurement part in this instrument is an embedded system, the AErms parameter is used to infer the leakage rate, and the microcontroller is used as the central handler. Before the instrument works, the key point is just completely turning off the valve for mounting an AE sensor without disassembling the valve. The measurement error of this instrument is shown in Table 1 [37]. The UKbased Score Group plc, to meet the market, developed the MIDAS Meter, which helps maintenance technicians to identify the leaking valves quickly and easily [66].

5.3. The Failure of Valves. The applications of AE technique in detecting failure of valves focused on the leakage of valves, identification of failure modes, and valve degradation [67]. Based on the opposite properties of AE signals and background noise, Nakamura and Terada used an AE sensor
TABLE 1: Error of measurement of their proposed instrument [37].

\begin{tabular}{lcc}
\hline $\begin{array}{l}\text { Actual leakage rate } \\
(\mathrm{mL} / \mathrm{s})\end{array}$ & $\begin{array}{c}\text { Calculated leakage } \\
\text { rate }(\mathrm{mL} / \mathrm{s})\end{array}$ & Error $(\%)$ \\
\hline 20 & 19 & 3.5 \\
40 & 42 & 4.7 \\
50 & 52 & 4.0 \\
100 & 92 & 7.8 \\
\hline
\end{tabular}

to effectively monitor the minor leak of pressurized valves [68]. Lee et al. used the AE technique to finish the detection of check valve degradation and service aging such as disk seat and hinge pin wear [69]. Seong et al. proposed a method in which the AE sensors were used for detecting the failures of check valves and developed a diagnostic algorithm to identify the type and the size of the failure of valve. A hydraulic test loop and a neural network model were involved in their study. The results showed that this method worked well in identification of failure and estimation of the relationship between the size and failure type. The RMS values of $\mathrm{AE}$ signal in different failure modes are shown in Figure 6 [70]. Yang et al. applied the AE technique to identify the internal leaky modes of globe valve, which could be classified as the untight closing and crack. It was tested in the valves and the results showed it worked effectively [71]. Sim et al. employed $\mathrm{AE}$ signal to detect valve failure in reciprocating compressor. Any abnormalities of the valve motion could be detected effectively by analyzing the RMS value. In their further study, the detection of other types of valve and the initiation of materials deformation in valves could be achieved [72]. Wang et al. proposed a method for detecting the actual working condition of a valve using the AE signal and the simulated valve motion. This method can easily distinguish the normal valve, valve flutter, and valve delayed closing conditions [73]. 


\section{The Cavitation}

The cavitation is a common occurrence in fluid flows. It will occur when the local static pressure is lower than the saturated vapor pressure at the working temperature. The growth and collapse of cavitation bubbles lead to the corrosion or pitting of metal surfaces. The cavitation is a big problem, which accelerates the process of valve failure.

Derakshan et al. realized the cavitation monitoring of hydraulic turbines through the measurement and analysis of the true RMS of AE signals [74, 75]. Neill et al. had a monitoring on the cavitation phenomenon of a centrifugal pump based on $\mathrm{AE}$ technique and got a more accurate result than vibration signal [76]. Alfayez et al. had a study on the features of incipient cavitation with the root-mean-square value of AE signal [77]. Čudina and Prezelj proposed the relationship between the discrete frequency component and the cavitation. It was concluded that the characteristic discrete frequency tone was closely linked with the cavitation process [78]. Håkansson et al. investigated the location and conditions of cavitation based on a high-pressure homogenizer model with two methods: the scattering of light from cavitation bubbles and the acoustical measurement [79]. Xu et al. found the gas velocity could elongate and strengthen the bubbles and increase the AE signals [80]. Husin et al. presented a method using the AE technology to detect the bubble inception and burst. All studies proved the feasibility that we could monitor the bubble condition and obtain the flow patterns during the phase gas-liquid flow by the $\mathrm{AE}$ technique [81].

Rahmeyer studied the noise limit of cavitation as well as the cavitation limits of incipient, critical, incipient damage, and choking cavitation for butterfly valves based on the analysis of experimental data. He set $85 \mathrm{~dB}$ as the limit of the cavitation noise level and discussed the effects of the limit on upstream pressure and valve size [82]. Osterman et al. put forward a visualization method for incipient cavitation detection and made a comparison with pressure oscillations measured by a hydrophone on the two different openings of the valve. It proved that the visualization method was more efficient than the hydrophone measurement [83]. Jazi and Rahimzadeh investigated the acoustic waveform of cavitation in the globe valve and analyzed the waveform and its important parameters by FFT [84]. They also explored the cavitation in globe valves with two different methods: characteristic diagrams and acoustic measurement [85]. So the method of detecting the cavitation in valves using the noise has not high precision because of the influence of ambient noise. The $\mathrm{AE}$ technique used in detecting cavitation of valves can be a good solution.

\section{Conclusions}

A review of the applications of $\mathrm{AE}$ techniques for detecting the condition and faults of valves was presented. The principle of $\mathrm{AE}$ was shown and the popular parameters analysis methods were discussed. The parameter of AErms is proved to have a strong relationship with the fluid parameters and the valve parameters, such as the valve types and valve size, the leakage rate, the inlet pressure, and the types of fluid. The detection of leakage, condition monitoring of faults, cavitation detection of valves, and portable measurement device were proposed in this review. The applications of new processing methods of AE signals including fast Fourier transform (FFT), wavelet transform, Hilbert-Huang transform (HHT), neural networks, and genetic algorithm in valves are presented. All results have shown that the $\mathrm{AE}$ technique can work well in the field of valves.

\section{Conflict of Interests}

The authors declare that there is no conflict of interests regarding the publication of this paper.

\section{Acknowledgments}

This work was supported by the National Natural Science Foundation of China (11272368, 51175532), by the Natural Science Foundation Project of CQ CSTC (cstc2013yykfb80007, cstc2013jcsf-nycgzhA80003, and cstc2014yykfA70003), and by the Scientific and Technological Research Program of Chongqing Municipal Education Commission (KJ140093).

\section{References}

[1] E. Meland, V. Henriksen, E. Hennie, and M. Rasmussen, "Spectral analysis of internally leaking shut-down valves," Measurement, vol. 44, no. 6, pp. 1059-1072, 2011.

[2] T. Juvik and T. Hermansen, "Online valve monitoring systems used on off-shore platforms in the North sea," in Proceedings of the 21st International Conference on Offshore Mechanics and Arctic Engineering (OMAE '02), pp. 333-337, American Society of Mechanical Engineers, June 2002.

[3] J. M. Rajtar and R. Muthiah, "Pipeline leak detection system for oil and gas flowlines," Journal of Manufacturing Science and Engineering, vol. 119, no. 1, pp. 105-109, 1997.

[4] F. Han, B. Song, T. Yu, and W. Cui, "Present state and prospects for valve reliability technique study," Machine Tool \& Hydraulics, vol. 9, p. 48, 2008 (Chinese).

[5] N. Tandon and A. Choudhury, "A review of vibration and acoustic measurement methods for the detection of defects in rolling element bearings," Tribology International, vol. 32, no. 8, pp. 469-480, 1999.

[6] G. Thompson and G. Zolkiewski, "An experimental investigation into the detection of internal leakage of gases through valves by vibration analysis," Proceedings of the Institution of Mechanical Engineers Part: E, vol. 211, no. 3, pp. 195-207, 1997.

[7] A. Püttmer and V. Rajaraman, "P3F-6 acoustic emission based online valve leak detection and testing," in Proceedings of the IEEE Ultrasonics Symposium (IUS '07), pp. 1854-1857, IEEE, October 2007.

[8] J. A. Musa, Application of acoustic emission (AE) technique in various materials (metal, woods and bricks) [Ph.D. thesis], Universiti Malaysia Sarawak, 2002.

[9] F. Tonolini, A. Sala, and G. Villa, "General review of developments in acoustic emission methods," International Journal of Pressure Vessels and Piping, vol. 28, no. 1, pp. 179-201, 1987. 
[10] D. Dornfeld, "Application of acoustic emission techniques in manufacturing," NDT \& E International, vol. 25, no. 6, pp. 259269, 1992.

[11] P. S. Pai and P. K. R. Rao, "Acoustic emission analysis for tool wear monitoring in face milling," International Journal of Production Research, vol. 40, no. 5, pp. 1081-1093, 2002.

[12] A. Behnia, H. K. Chai, and T. Shiotani, "Advanced structural health monitoring of concrete structures with the aid of acoustic emission," Construction and Building Materials, vol. 65, pp. 282302, 2014.

[13] J. I. Ukpai, R. Barker, X. Hu, and A. Neville, "Determination of particle impacts and impact energy in the erosion of X65 carbon steel using acoustic emission technique," Tribology International, vol. 65, pp. 161-170, 2013.

[14] J. I. Ukpai, R. Barker, X. Hu, and A. Neville, "Exploring the erosive wear of X65 carbon steel by acoustic emission method," Wear, vol. 301, no. 1-2, pp. 370-382, 2013.

[15] A. Mostafapour and S. Davoudi, "Analysis of leakage in high pressure pipe using acoustic emission method," Applied Acoustics, vol. 74, no. 3, pp. 335-342, 2013.

[16] W. Liang, L. Zhang, Q. Xu, and C. Yan, "Gas pipeline leakage detection based on acoustic technology," Engineering Failure Analysis, vol. 31, pp. 1-7, 2013.

[17] C. Jomdecha, A. Prateepasen, and P. Kaewtrakulpong, "Study on source location using an acoustic emission system for various corrosion types," NDT \& E International, vol. 40, no. 8, pp. 584593, 2007.

[18] P. Lura, J. Couch, O. M. Jensen, and J. Weiss, "Early-age acoustic emission measurements in hydrating cement paste: evidence for cavitation during solidification due to self-desiccation," Cement and Concrete Research, vol. 39, no. 10, pp. 861-867, 2009.

[19] P. Nivesrangsan, J. A. Steel, and R. L. Reuben, "Acoustic emission mapping of diesel engines for spatially located time series-part II: spatial reconstitution," Mechanical Systems and Signal Processing, vol. 21, no. 2, pp. 1084-1102, 2007.

[20] R. K. Miller and P. McIntire, Nondestructive Testing Handbook: Volume 5 Acoustic Emission Testing, American Society for Nondestructive Testing, Columbus, Ohio, USA, 1987.

[21] N. Tandon and A. Choudhury, "A review of vibration and acoustic measurement methods for the detection of defects in rolling element bearings," Tribology International, vol. 32, no. 8, pp. 469-480, 1999.

[22] K. A. El-Shorbagy, "An investigation into noise radiation from flow control valves with particular reference to flow rate measurement," Applied Acoustics, vol. 16, no. 3, pp. 169-181, 1983.

[23] M. A. Sharif and R. I. Grosvenor, "Internal valve leakage detection using an acoustic emission measurement system," Transactions of the Institute of Measurement and Control, vol. 20, no. 5, pp. 233-242, 1998.

[24] S.-G. Lee, J.-H. Park, K.-B. Yoo, S.-K. Lee, and S.-Y. Hong, "Evaluation of internal leak in valve using acoustic emission method," Key Engineering Materials, vol. 326-328, pp. 661-664, 2006.

[25] W. Kaewwaewnoi, Theoretical and experimental investigation to measure internal leakage of fluid through valves using acoustic emission [Ph.D. Progress Report], King's Mongkut University of Technology, Thonburi, Thailand, 2008.

[26] M.-R. Lee, J.-H. Lee, and J.-T. Kim, "Condition monitoring of a nuclear power plant check valve based on acoustic emission and a neural network," Transactions of the ASME-Journal of Pressure Vessel Technology, vol. 127, no. 3, pp. 230-236, 2005.
[27] W. Kaewwaewnoi, A. Prateepasen, and P. Kaewtrakulpong, "Investigation of the relationship between internal fluid leakage through a valve and the acoustic emission generated from the leakage," Measurement, vol. 43, no. 2, pp. 274-282, 2010.

[28] M. Noipitak, A. Prateepasen, and W. Kaewwaewnoi, "A relative calibration method for a valve leakage rate measurement system," Measurement, vol. 44, no. 1, pp. 211-218, 2011.

[29] T. Yan, P. Theobald, and B. E. Jones, "A self-calibrating piezoelectric transducer with integral sensor for in situ energy calibration of acoustic emission," NDT \& E International, vol. 35, no. 7, pp. 459-464, 2002.

[30] D. Mba and R. B. K. N. Rao, "Development of acoustic emission technology for condition monitoring and diagnosis of rotating machines: bearings, pumps, gearboxes, engines, and rotating structures," Shock and Vibration Digest, vol. 38, no. 2, pp. 3-16, 2006.

[31] Y. H. Ali, R. Abd Rahman, and R. I. R. Hamzah, "Acoustic emission signal analysis and artificial intelligence techniques in machine condition monitoring and fault diagnosis: a review," Jurnal Teknologi, vol. 69, no. 2, 2014.

[32] J. Dickey, J. Dimmick, and P. M. Moore, "Acoustic measurement of valve leakage rates," Materials Evaluation, vol. 36, no. 1, pp. $67-77,1978$.

[33] Q. Gao, L. Li, H. Rao, and J. Yang, "Research on the relationship between internal fluid leakage through a valve and the acoustic emission features generated from the leakage," Journal of Engineering for Thermal Energy and Power, vol. 26, no. 5, 2011.

[34] Y. Mingwei and G. Rongsheng, Acoustic Emission Testing, Southeast University Press, Nanjing, China, 1991.

[35] W. Kaewwaewnoi, A. Prateepasen, and P. Kaewtrakulpong, "Measurement of valve leakage rate using acoustic emission," in Proceedings of the International Conference on Electrical Engineering/Electronics, Computer, Telecommunications, and Information Technology (ECTI '05), pp. 597-600, 2005.

[36] P. Chen, P. S. K. Chua, and G. H. Lim, "A study of hydraulic seal integrity," Mechanical Systems and Signal Processing, vol. 21, no. 2, pp. 1115-1126, 2007.

[37] A. Prateepasen, W. Kaewwaewnoi, and P. Kaewtrakulpong, "Smart portable noninvasive instrument for detection of internal air leakage of a valve using acoustic emission signals," Measurement, vol. 44, no. 2, pp. 378-384, 2011.

[38] A. A. Pollock and S. Y. S. Hsu, "Leak detection using acoustic emission," Journal of Acoustic Emission, vol. 1, pp. 237-243, 1982.

[39] Y. Jiang, Q.-C. Gong, Q. Ye, and C.-L. Liu, “The theoretical analysis and experiments of using ultrasonic to inspect the leak amount," China Academic Journal Electronic Publishing House, no. 1, 2005 (Chinese).

[40] Q.-X. Gao, L.-P. Li, H.-D. Rao, J. Yang, and Y.-J. Zhu, "Acoustic emission theory and testing technology for quantitative diagnosis of valve leakages," Journal of Chinese Society of Power Engineering, vol. 32, no. 1, pp. 42-46, 2012 (Chinese).

[41] X. Li, "A brief review: acoustic emission method for tool wear monitoring during turning," International Journal of Machine Tools and Manufacture, vol. 42, no. 2, pp. 157-165, 2002.

[42] A. Albarbar, F. Gu, A. D. Ball, and A. Starr, "Acoustic monitoring of engine fuel injection based on adaptive filtering techniques," Applied Acoustics, vol. 71, no. 12, pp. 1132-1141, 2010.

[43] C. Zhou and Y. Zhang, "Particle filter based noise removal method for acoustic emission signals," Mechanical Systems and Signal Processing, vol. 28, pp. 63-77, 2012. 
[44] H. Jin, L. Zhang, W. Liang, and Q. Ding, "Integrated leakage detection and localization model for gas pipelines based on the acoustic wave method," Journal of Loss Prevention in the Process Industries, vol. 27, no. 1, pp. 74-88, 2014.

[45] M. Ahadi and M. S. Bakhtiar, "Leak detection in waterfilled plastic pipes through the application of tuned wavelet transforms to Acoustic Emission signals," Applied Acoustics, vol. 71, no. 7, pp. 634-639, 2010.

[46] C. Lu, P. Ding, and Z. Chen, "Time-frequency analysis of acoustic emission signals generated by tension damage in CFRP," Procedia Engineering, vol. 23, pp. 210-215, 2011.

[47] Z. Yang, Z. Yu, C. Xie, and Y. Huang, "Application of HilbertHuang Transform to acoustic emission signal for burn feature extraction in surface grinding process," Measurement, vol. 47, no. 1, pp. 14-21, 2014.

[48] W. Liang and L. Zhang, "A wave change analysis (WCA) method for pipeline leak detection using Gaussian mixture model," Journal of Loss Prevention in the Process Industries, vol. 25, no. 1, pp. 60-69, 2012.

[49] T. T. Le, J. Watton, and D. T. Pham, "An artificial neural network based approach to fault diagnosis and classification of fluid power systems," Proceedings of the Institution of Mechanical Engineers. Part I: Journal of Systems and Control Engineering, vol. 211, no. 4, pp. 307-317, 1997.

[50] J. Sun, Q. Xiao, J. Wen, and F. Wang, "Natural gas pipeline small leakage feature extraction and recognition based on LMD envelope spectrum entropy and SVM," Measurement, vol. 55, pp. 434-443, 2014.

[51] W. M. Park, "Development of a diagnostic algorithm with acoustic emission sensors and neural networks for check valves," Journal of the Korean Nuclear Society, vol. 36, no. 6, pp. 540-548, 2004.

[52] H. Huang, A. Li, and X. Lin, "Application of PSO-based wavelet neural network in tool wear monitoring," in Proceedings of the IEEE International Conference on Automation and Logistics (ICAL '07), pp. 2813-2817, August 2007.

[53] S. M. Jafari, H. Mehdigholi, and M. Behzad, "Valve fault diagnosis in internal combustion engines using acoustic emission and artificial neural network," Shock and Vibration, vol. 2014, Article ID 823514, 9 pages, 2014.

[54] Y. L. Mao, G. Kinsman, and W. W. Duley, "Real-time fast Fourier transform analysis of acoustic emission during $\mathrm{CO}_{2}$ laser welding of materials," Journal of Laser Applications, vol. 5, no. 2, pp. 17-22, 1993.

[55] P. Antonaci, P. Bocca, and D. Masera, "Fatigue crack propagation monitoring by Acoustic Emission signal analysis," Engineering Fracture Mechanics, vol. 81, pp. 26-32, 2012.

[56] J. W. Allen, W. F. Hartman, and J. C. Robinson, "Acoustic monitoring of power-plant valves," Final Report, Technology for Energy, Knoxville, Tenn, USA, 1982.

[57] H. D. Haynes, "Evaluation of check valve monitoring methods," Nuclear Engineering and Design, vol. 134, no. 2-3, pp. 283-294, 1992.

[58] S. Lee Y, J. Jeon S, and J. Lyou, "Condition monitoring of check valve using neural network," in Proceedings of the International Academic Conference, pp. 2198-2202, June 2005.

[59] J.-H. Lee, M.-R. Lee, J.-T. Kim, and J.-S. Kim, "Analysis of acoustic emission signals for condition monitoring of check valve at nuclear power plants," Key Engineering Materials, vol. 270-273, pp. 531-536, 2004.
[60] J.-H. Lee, M.-R. Lee, J.-T. Kim, V. Luk, and Y.-H. Jung, "A study of the characteristics of the acoustic emission signals for condition monitoring of check valves in nuclear power plants," Nuclear Engineering and Design, vol. 236, no. 13, pp. 1411-1421, 2006.

[61] M. Boken, "Valve monitoring system and method," U.S. Patent 7,318,350[P], 2008.

[62] I. N. B. M. Shukri, G. Y. Mun, and R. B. Ibrahim, "A study on control valve fault incipient detection monitoring system using acoustic emission technique," in Proceedings of the 3rd International Conference on Computer Research and Development (ICCRD '11), vol. 4, pp. 365-370, IEEE, Shanghai, China, March 2011.

[63] R. Bayindir and H. Ates, "Low-cost and high sensitively microcontroller based control unit for a friction welding machine," Journal of Materials Processing Technology, vol. 189, no. 1-3, pp. 126-131, 2007.

[64] C. Jomdecha, A. Prateepasen, P. Kaewtrakulpong, and P. Thungsuk, "Corrosion-source location by an FPGA-PC based acoustic emission system," in Proceedings of the IEEE Region 10 Annual International Conference (TENCON '04), vol. 4, pp. 500-601, 2004.

[65] J. G. Dimmick, J. R. Nicholas Jr., J. W. Dickey, and P. M. Moore, "Acoustical valve leak detector for fluid system maintenance," Naval Engineers Journal, vol. 91, no. 2, pp. 71-83, 1979.

[66] Score (Europe) Limited and Glenugie Engineering Works, "Identifying leaking valves quickly and easily using acoustic emissions measurement technology," Sealing Technology, vol. 2013, no. 1, pp. 11-12, 2013.

[67] A. E. G. Benz, "Use of acoustic emission techniques for detection of discontinuities," Materials Evaluation, vol. 56, no. 10, pp. 1215-1222, 1998.

[68] T. Nakamura and M. Terada, "Development of leak monitoring system for pressurizer valves," Progress in Nuclear Energy, vol. 15, pp. 175-179, 1985.

[69] J. H. Lee, M. R. Lee, J. T. Kim et al., "Condition monitoring of a check valve for nuclear power plants by means of acoustic emission technique," in Proceedings of the 17th International Conference on Structural Mechanics in Reactor Technology, Prague, Czech Republic, August 2003.

[70] S.-H. Seong, S. Hur, J.-S. Kim et al., "Development of diagnosis algorithm for the check valve with spectral estimations and neural network models using acoustic signals," Annals of Nuclear Energy, vol. 32, no. 5, pp. 479-492, 2005.

[71] J. Yang, L. Li, H. Rao, Y. Zhu, and G. Liu, "Diagnosis of valve leakage fault patterns based on acoustic emission detection," Journal of Chinese Society of Power Engineering, vol. 33, no. 6, pp. 455-483, 2013.

[72] H. Y. Sim, R. Ramli, A. A. Saifizul, and M. A. K. Abdullah, "Empirical investigation of acoustic emission signals for valve failure identification by using statistical method," Measurement, vol. 58, pp. 165-174, 2014.

[73] Y. Wang, C. Xue, X. Jia, and X. Peng, "Fault diagnosis of reciprocating compressor valve with the method integrating acoustic emission signal and simulated valve motion," Mechanical Systems and Signal Processing, vol. 56-57, pp. 197-212, 2015.

[74] O. Derakshan, J. R. Houghton, R. K. Jones et al., "Cavitation monitoring of hydroturbines with true-rms acoustic emission measurement," Journal of Acoustic Emission, vol. 8, no. 1-2, pp. 5223-5226, 1989.

[75] "Special supplement-extended summaries of papers to be presented at the world meeting on acoustic emission, Charlotte, 
North Carolina, USA, 20-23 Mar. 1989," NDT \& E International, vol. 27, no. 4, p. 219, 1994.

[76] G. D. Neill, R. L. Reuben, P. M. Sandford, E. R. Brown, and J. A. Steel, "Detection of incipient cavitation in pumps using acoustic emission," Proceedings of the Institution of Mechanical Engineers Part E, vol. 211, no. 4, pp. 267-277, 1997.

[77] L. Alfayez, D. Mba, and G. Dyson, "The application of acoustic emission for detecting incipient cavitation and the best efficiency point of a $60 \mathrm{~kW}$ centrifugal pump: case study," NDT \& E International, vol. 38, no. 5, pp. 354-358, 2005.

[78] M. Čudina and J. Prezelj, "Detection of cavitation in situ operation of kinetic pumps: effect of cavitation on the characteristic discrete frequency component," Applied Acoustics, vol. 70, no. 9, pp. 1175-1182, 2009.

[79] A. Håkansson, L. Fuchs, F. Innings, J. Revstedt, B. Bergenståhl, and C. Trägårdh, "Visual observations and acoustic measurements of cavitation in an experimental model of a high-pressure homogenizer," Journal of Food Engineering, vol. 100, no. 3, pp. 504-513, 2010.

[80] W. Xu, Z. Lai, D. Wu, and L. Wang, "Acoustic emission characteristics of underwater gas jet from a horizontal exhaust nozzle," Applied Acoustics, vol. 74, no. 6, pp. 845-849, 2013.

[81] S. Husin, A. Addali, and D. Mba, "Feasibility study on the use of the Acoustic Emission technology for monitoring flow patterns in two phase flow," Flow Measurement and Instrumentation, vol. 33, pp. 251-256, 2013.

[82] W. J. Rahmeyer, "Cavitation noise from butterfly valves," Nuclear Engineering and Design, vol. 72, no. 3, pp. 297-301, 1982.

[83] A. Osterman, M. Hočevar, B. Širok, and M. Dular, "Characterization of incipient cavitation in axial valve by hydrophone and visualization," Experimental Thermal and Fluid Science, vol. 33, no. 4, pp. 620-629, 2009.

[84] A. M. Jazi and H. Rahimzadeh, "Waveform analysis of cavitation in a globe valve," Ultrasonics, vol. 49, no. 6-7, pp. 577-582, 2009.

[85] A. Masjedian Jazi and H. Rahimzadeh, "Detecting cavitation in globe valves by two methods: characteristic diagrams and acoustic analysis," Applied Acoustics, vol. 70, no. 11-12, pp. 14401445, 2009. 

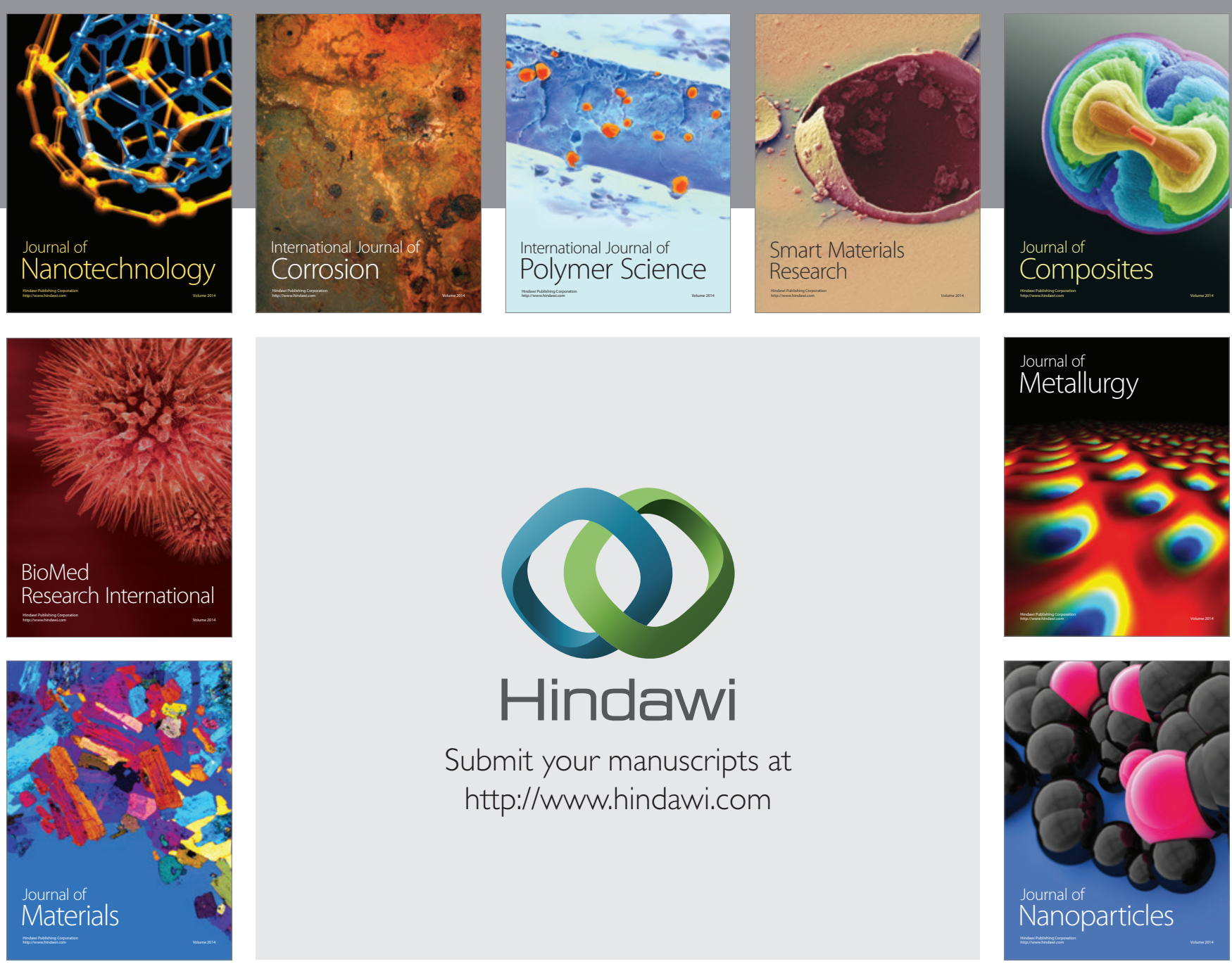

Submit your manuscripts at http://www.hindawi.com
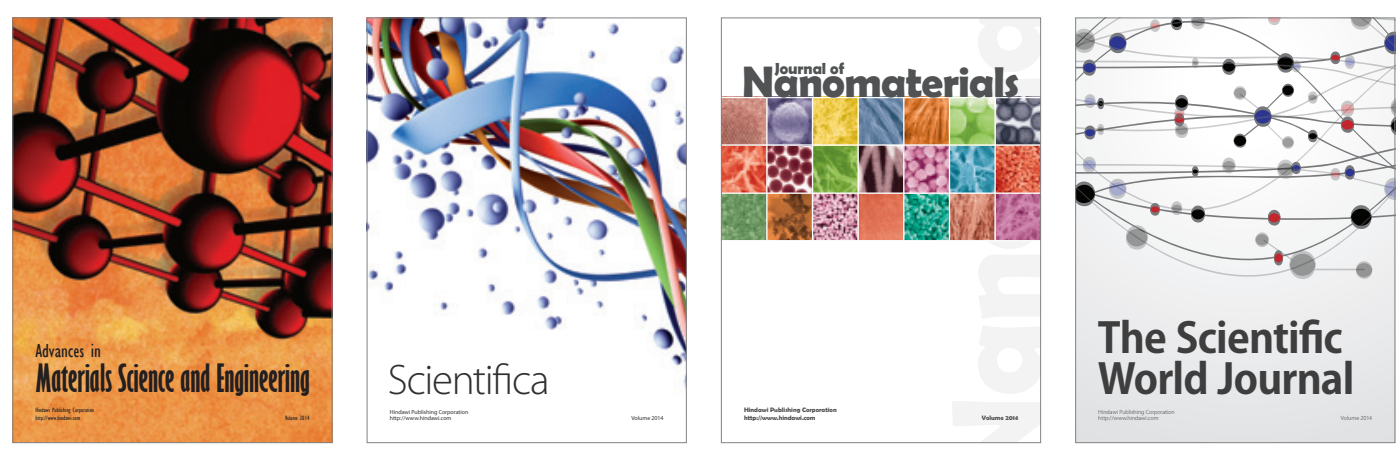

\section{The Scientific World Journal}
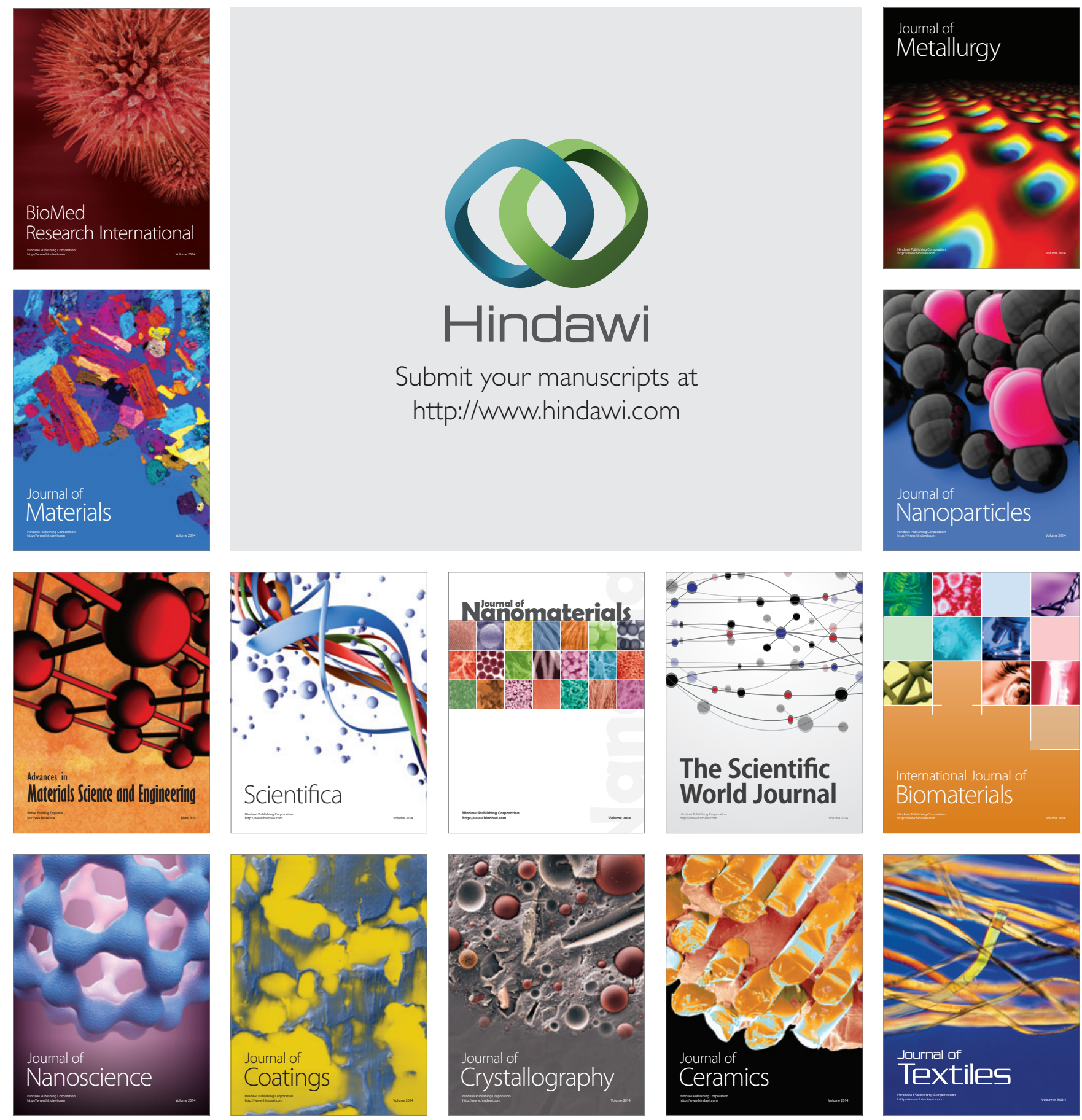